\title{
Creative Learning Design in Social Studies to Promote Productive Citizenship of Secondary School Students
}

\author{
Rattikorn Chanchumni ${ }^{1} \&$ Charin Mangkhang ${ }^{1}$ \\ ${ }^{1}$ Faculty of Education, Chiang Mai University, Thailand \\ Correspondence: Rattikorn Canchumni, Kankanok Ville14, Sankamphaeng Rd, 116/300 Sankamphaeng, \\ Sankamphaeng District, Chiang Mai, Thailand. E-mail: ratti2828@gmail.com
}

Received: September 2, 2021

Accepted: October 6, $2021 \quad$ Online Published: October 26, 2021

doi:10.5539/hes.v11n4p84

URL: https://doi.org/10.5539/hes.v11n4p84

\begin{abstract}
The purposes of this research are: 1) to study the creative learning in social studies to promote productive citizenship of secondary school students; and 2) to design the guidelines for such learning. This research implements the methodology of action research, consisting of 8 samples: 1) 1 school principal and 2 social studies teachers; and 2) 5 learning management experts. The samples are chosen by the purposive sampling method. Research tools consist of 1) unstructured interview form; and 2) appropriateness assessment form for the guidelines of creative learning in social studies to promote productive citizenship of secondary school students. Methods of data analysis consists of content analysis, and descriptive analysis, in addition to calculation of the means and standard deviation. Study results revealed that:

1. Creative learning in social studies to promote productive citizenship of secondary school students consists of the development of 4 minds, including: 1) critical mind; 2) creative mind; 3) productive mind; and 4) responsible mind. And 2. The guidelines of creative learning in social studies to promote productive citizenship of secondary school students consist of 4 subjects and 8 learning management plans. The effectiveness of the guidelines in terms of the learning management was evaluated as excellent.
\end{abstract}

Keywords: creative learning design, productive citizenship, social studies, secondary education

\section{Introduction}

Learning management of social studies is an essential process of the skills development for learners to become a global citizens who are capable of learning to live happily with others, and capable of applying their knowledge to adaptation to the changing society with balance and sustainability (Boonthongtherng, 2009). Learner development in accordance with the basic educational curriculum focuses on the following desirable characteristics: 1) communication skills; 2) thinking skills; 3) problem solution skills; 4) living skills; and 5) technology skills. These characteristics are expected to enhance learners with the skills of living in the society with happiness as a Thai and global citizenship (Mangkhang, 2017).

Development of learner skills requires designing and learning activities corresponding to each factor, which includes: 1) intellectual skill development, in which learners are expected to be capable of learning from various sources, in contexts of inside and outside the classroom; 2) social skill development, in which learners are capable of applying their career skills in order to achieve their career success through suggestions, discussion, and summarization which contribute to decision making; and 3) development of affective domain and characteristics; where learners are capable of applying the knowledge and skills obtained though the activities to the promotion of values and attitudes of information acquisition (Phinlaw, 2013).

Therefore, social studies pedagogy requires the learning methods which fulfill learning experience for the learners through encouragement of thinking, ability, skills, good values and attitudes. Additionally, the curriculum must correspond to the age and maturity of learners, in addition to encouraging self-learning and self-development through the knowledge obtained from the classroom. This process consists of: 1) Intellectual skills development. Refers to the learning management process which enhances learners with knowledge and comprehension of the subject, which includes thinking tools, thinking process, and thinking skills such as analytic thinking, synthetic thinking, critical thinking, solution thinking, and creative thinking. It also includes the knowledge obtained from the integration of surrounding topics. 2) Social skills development refers to the 
process of learning management which focuses on practical learning to enhance basic life skills, such as self-knowledge, thinking skills, decision making, problem solution, information search, adaptation, communication and relationship, planning, management, and teamwork. 3) Attitude and characteristic development refers to the process of learning management which focuses on development of appropriate attitude and charecteristics to the society of learners, such as diligence, frugality, honesty, diligence, and dharma, which learners are expected to apply to their own living (Panit, 2012; Mangkhang, \& Kaewpanya, 2021).

Consequently, skill development in context of secondary school students requires examination of the education, since it is an extremely essential factor which contributes to the development of abilities, skills, and expertises. Since these attributes are essential for national development, educational institutions play an important role in learning management to develop the skills and to enhance the power inside learners, in accordance with the National Education Act B.E. 2542 (1999), B.E. 2545 (2002) ( $2^{\text {nd }}$ amendment), and B.E. 2553 (2010) $\left(3^{\text {rd }}\right.$ amendment). Additionally, as a part of innovation-based economic policy, Thai government has announced the Thailand 4.0 era project, which focuses on the application of creativity, innovation, science, technology, research and development, causing creativity to become necessary for invention. Accordingly, Thai education system in the 4.0 era focuses on creative and productive learning which contributes to self-development, and eventually a "product" which benefits the society and the nation (Sinlarat et al., 2017, Hannongbua, 2016).

Creative and production learning refers to learning management which focus on the development of critical mind, creative mind, productive mind, and responsible mind for the learners, called the "CCPR Model". This concept corresponds to the concept of $21^{\text {st }}$ century education, which focuses on critical mind, creative mind, and teamwork (Thienkasem, Ponathong, \& Yongsorn, 2020). Based on the task-based learning, creative learning management of social studies to promote productive citizens provides learners with the opportunities of practical learning by working on the tasks and presenting their production, all of which have clear operation processes (Ellis, 2003; Mangkhang, Yimsawat, \& Kaewpanya, 2021).

Therefore, we consider that designing a digital-based creative learning in social studies to promote productive citizenship of secondary school students in essential. We expect that this research will contribute to evaluation of the learning management plan implementation, and practical implementation in the education system, by focusing on cooperation with educational institutions and teachers. As a result, designing such the the learning management plan to correspond with learner demands, and eventually living skills, will become practicable.

\section{Research Purposes}

1) To study the creative learning in social studies to promote productive citizenship of secondary school students

2) To design the guidelines of creative learning in social studies to promote productive citizenship of secondary school students.

\section{Methodology}

This research implements the methods of action research, while the data is analyzed with the methods of content analysis and descriptive analysis. Statistics applied in this research consists of mean and standard deviation.

\subsection{Population and Samples}

The population of this research consists of 2 primary groups: 1) school administrators and social study teachers; and 2) learning management experts. Using the purposive sampling, we determined the sample number of each group as follows:

1) One school administrator and 2 social study teachers.

2) Five learning management experts.

\subsection{Research Tools}

Research tools implemented on the data collection consist of:

1) Unstructured interview form.

2) Appropriateness assessment form for the guidelines of creative learning in social studies to promote productive citizenship of secondary school students.

\subsection{Data Collection}

1) Documentary study. The data is collected from documents, books, journals which describe related theories, concepts, and researches. Collected data is applied to the analysis of the research topic.

2) Two-stage field study, which consist of: Stage 1: Situational analysis. Refers to collection of qualitative data 
though the synthesis of documents and researches related to learning management of creative social studies. The applied analysis result is then applied to the design of the learning management. Stage 2: Design and development It refers to collection of quantitative data through design, development, and calculate the performance of the learning management guidelines, of which the quality is evaluated by learning management experts. In this stage, the evaluation form of the appropriateness of creative social study learning management is utilized to determine the effectiveness of the learning management guidelines.

\subsection{Research Model}

This research is a mixed-method research, in which the research model is determined as follows:

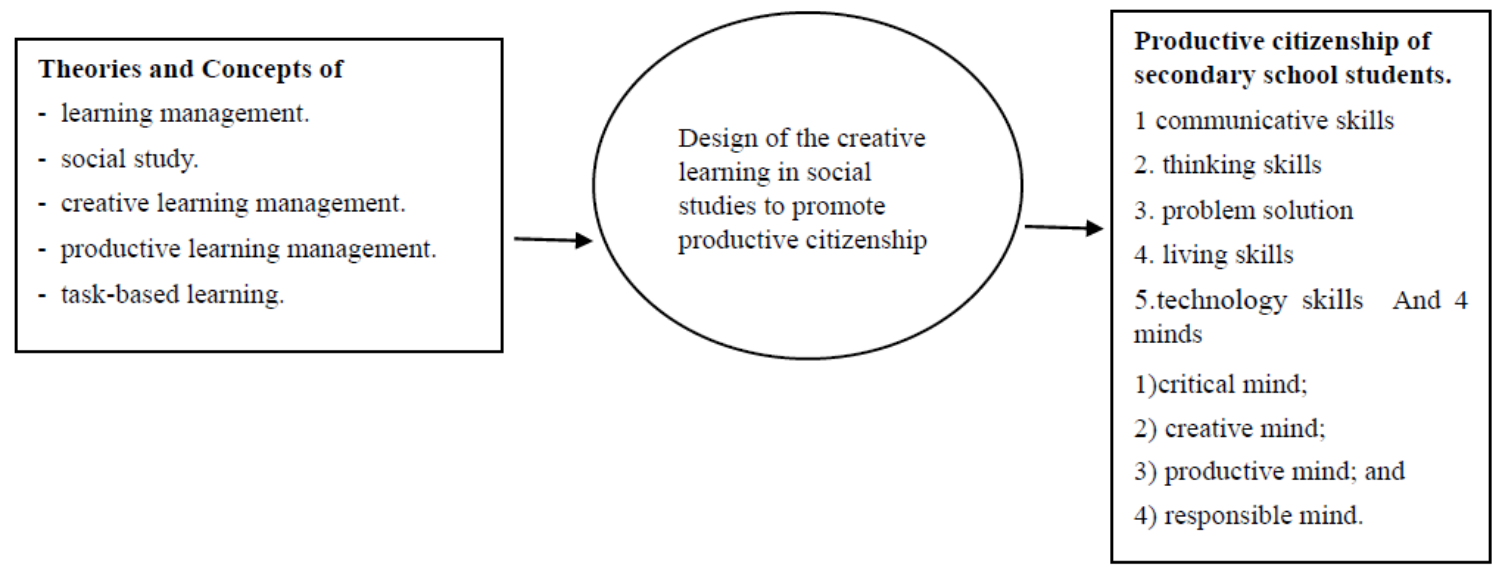

Figure 1. Research model

Source: Rattikorn Chanchumni \& Charin Mangkhang

\section{Results}

The creative learning in social studies to promote productive citizenship of secondary school consists of 4 skills: 1) critical mind; 2) creative mind; 3) productive mind; and 4) responsible mind. It is expected that students are enhanced with integral skills, and that schools and households cooperate to achieve effective learning management.

Applying the "CCPR Model" of Phaithoon Sinlarat (2016), the guidelines of creative learning in social studies to promote productive citizenship of secondary school can be categorized into 4 subjects and 8 learning management plans as follows:

Table 1. Development process of the subjects and creative learning management plans

\begin{tabular}{|c|c|c|}
\hline $\begin{array}{l}\text { DTBL Learning } \\
\text { Management Design }\end{array}$ & Subject & Creative Learning Management Plans \\
\hline 1. Analysis & $\begin{array}{l}1^{\text {st }} \text { Subject: } \\
\text { Community } \\
\text { Analysis. }\end{array}$ & $\begin{array}{l}\text { 1. Analysis of local travelling destination } \\
\text { to promote creative learning. } \\
\text { 2. Choosing local travelling destinations. }\end{array}$ \\
\hline 2. Product Design & $\begin{array}{l}2^{\text {nd }} \text { Subject: Local } \\
\text { Travel Map Design }\end{array}$ & $\begin{array}{l}\text { 1. Designing a digital local travel map to promote } \\
\text { creative ideas for oneself and the society. } \\
\text { 2. Execution of the design plan, }\end{array}$ \\
\hline 3. Job Production & $\begin{array}{l}3^{\text {rd }} \text { Subject: Local } \\
\text { Travel Map Production }\end{array}$ & $\begin{array}{l}\text { 1. Producing a digital local travel map } \\
\text { to promote productive ideas. } \\
\text { 2. Execution of the production plan. }\end{array}$ \\
\hline 4. Presentation & $\begin{array}{l}4^{\text {th }} \text { Subject: Local } \\
\text { Travel Map } \\
\text { Presentation }\end{array}$ & $\begin{array}{l}\text { 1. Presentation of the final production } \\
\text { to raise local consciousness of the student. } \\
\text { 2. Establishment of a digital network to } \\
\text { present the final production. }\end{array}$ \\
\hline
\end{tabular}


Evaluation results of the appropriateness of the learning management plans revealed significant suggestions of the experts in terms of the learning management plans for creative social studies as follows:

Table 2. Evaluation results of the appropriateness of the learning management plans for creative social studies

\begin{tabular}{|c|c|c|c|}
\hline Evaluation item & $\bar{X}$ & SD & Result \\
\hline $\begin{array}{l}\text { 1. The design of learning management plans indicates comprehension, } \\
\text { accessibility, and development. }\end{array}$ & 4.60 & 0.49 & Highest \\
\hline $\begin{array}{l}\text { 2. Learning management plans contain complete elements, and enhance } \\
\text { the productive citizen knowledge, skills, process, and capability of the students. }\end{array}$ & 4.59 & 0.50 & Highest \\
\hline $\begin{array}{l}\text { 3. Learning management plans include the activities which correspond to } \\
\text { the learning of the } 4.0 \text { era. }\end{array}$ & 4.62 & 0.49 & Highest \\
\hline agement nlans are diverse and focus on learners & 4.62 & 0.49 & Highest \\
\hline he changes of cognitive & 4.56 & 0.50 & Highest \\
\hline tent with the criteria and $i$ & 4.59 & 0.49 & Highest \\
\hline the students to discover and & 4.52 & 0.50 & Highest \\
\hline ources are appropriate for creative learning & 4.57 & 0.50 & Highest \\
\hline $\begin{array}{l}\text { 9. Learning management plans for creative social studies include } \\
\text { indicators and evaluation, and clearly specify the tools for such purposes. }\end{array}$ & 4.50 & 0.50 & Highest \\
\hline $\begin{array}{l}\text { 10. Learning management plans for creative social studies include } \\
\text { indicators and evaluation which integrate the behaviors specified in the } \\
\text { indicators of the social study subject. }\end{array}$ & 4.57 & 0.50 & Highest \\
\hline Overall & 4.57 & 0.49 & Highest \\
\hline
\end{tabular}

Table 2 indicates that the overall appropriateness of the creative learning management plan for social studies is at the highest level $(\bar{X}=4.57, \mathrm{SD}=0.49)$, and all 10 items has the highest appropriateness level.

\section{Discussion}

Study results in terms of the first research purpose revealed that the creative learning in social studies to promote productive citizenship of secondary school consists of 4 skills: 1) critical mind;2) creative mind; 3) productive mind; and 4) responsible mind. This corresponds to Sinlarat (2016), who suggests that good guidelines of "creative and productive education" include:

1) Critical mind. In a consumerist society, learners require thinking skills to understand, learn, and avoid becoming a victim of economic, political, and social propagandas.

2) Creative mind. Apart from critical thinking, creative mind which contribute to the learners themselves and their society is also necessary, because critical mind alone is not capable of creating new things.

3) Productive mind. New ideas are transformed into discrete production.

4) Responsible mind. After achieving the aforementioned minds, responsibility to oneself and the society is required as an essential moral foundation.

The study results also correspond to Add reference, who suggests that creative thinking consists of 4 stages as follows:

1) Preparation. It refers to problem setting, observation, and research.

2) Incubation. It refers to the period where the problems are set aside.

3) Illumination. It refers to (add information)

4) Verification. It refers to the examination of new thoughts.

The concept of Wallas is an essential foundation of learning pattern development, and creativity pedagogy. Incubation and llumination processes occur instantaneously, illumination that creativity is an impossible unconscious process of the brain. However, suggestions of the first and fourth stages indicate that creativity begins with the intention of the preparation (problem setting, observation, and research) and finished with critical cerification. This suggests that creativity and analysis have supportive relationship rather than being opposite to each other. In other words, an individual with creative mind not only learns to study and analyze, but also learns 
how to perceive critically. Such individual believes in surprise, but immediately refrains from decision.

Baron's (1996) concept of the creative learning in social studies to promote productive citizenship gives precedence to unconscious creativity and process of coincidence. His model, referred to as the "Psychic Creation Model" categorizes such process into 4 stages: conception, gestation, parturition, and bringing up the baby. In other words, Baron's concept of the creativity supports the idea that creativity is a mysterious process related to the subconsciousness which is under control of the creator themselves. This corresponds to the concept of Bandrowski (1996), who suggests the process of the thinking strategy, referred to as "A Model for Creative Strategic Planning", which consists of: analysis, creativity, judgement, and planning which includes action planning. Therefore, it can be said that the creativity process is related to critical mind, creative mind, productive mind, and responsible mind. Overall, the creativity process means the balance of imagination and critical mind. Old thinking process focused the result of creativity occurred from subconsciousness, which is outside the influence of an individual, while new thinking process focuses more on new thoughts under the influence of an individual, and has a propose to apply such thoughts top the action. Therefore, actions should be prioritized over sole imagination.

Study results in terms of the second purpose, designing the creative learning management plan of social studies to promote productive citizenship of secondary school students, revealed that the effectiveness level of the learning management through activities based on "task-based learning" and "CCPR model" processes was evaluated as highest. This indicates that the creative learning management plan based on the "task-based learning" and "CCPR model" which focuses on self-learning will contribute to the development of learners into a lifelong learning individual capable of adapting themselves to the society. Task-based learning is considered one of the learning methods in which learners will become capable of self-learning, in addition to obtaining knowledge, skills, and morals required for mutual living in current society. Self-learning skills should be included in the development of secondary school students, probably because of constant changes.

These study results correspond to sinlarat (2011), who suggests that creative mind is the most essential for secondary school students, and most desired for the society, followed by productive mind, critical mind, and responsible mind, respectively. Additionally, Monthirat (2016) explains that task-based learning includes the learning management process which contributes to the actions of learners, step-by-step learning, and self-learning. Learners are also provided with opportunities of creative thinking to create their own unique works.

Similarly, Guilford (1967) also states that creativity is a brain capability which enables convergent thinking, a complex and diverse thinking process, which may contribute to new inventions. Convergent thinking consists of initiative, reflexive, resilient, and delicate thinkings. If learners are assigned the tasks which sufficiently focuses on convergent thinking, the development of creativity will become possible. This corresponds to the concept of reference which suggests that development of creativity is possible. Therefore, task-based learning management allows them to understand the skills and potentials of their students, in addition to encouraging the students to express their own skills, which contributes to self-comprehension and self-improvement. Additionally, teachers will understand the differences of each student, which contribute to management of learning activity plans and student action plans.

\section{Conclusion}

This research has provided teachers with learning management plans for social study, which enhances the students with knowledge and comprehension regarding creative and productive thinking process for self-development. Such process is expected to enhance students with knowledge and interest in the creative thinking, productive thinking, critical thinking, and responsible thinking skills, all of which are essential skills which contributes to optimal living skills.

\section{Suggestion}

We propose the suggestions regarding this research as follows:

\subsection{Application of the Study Results}

1) Teachers should tudy the learning management plan of creative learning in social studies to promote productive citizenship of secondary school students, in accordance with the learner demands.

2) Evaluation of the learning management plan should be conducted by students, so that the results may be applied the improvement of the plan. 


\subsection{Further Research}

1) The learning management plan should be developed for other grades.

2) The learning management plan should be developed alongside different learning processes to improve the learning management.

3) Techniques of the creative and productive learning should be applied to the development of other subjects in the curriculum of social studies, religion, and culture.

\section{References}

Anderson, L. W., \& Krathwohl, D. R. (Eds.). (2001). A Taxonomy for Learning, Teaching, and Assessing: A Revision of Bloom's Taxonomy of Educational Objectives. NewYork: Longman.

Boonthongtheng, P. (2009). Changes in the principles of Teaching course both theoretical and Phenomena from the Past to the Present. Education Journal, 5(October-November), 85-91.

BuaKlee, C. (2014). Academic Papers: Application of Dr. Edward de Bono's Ideas for Interesting Print Designs. Thai version in the field of humanities, social sciences and arts and international edition Humanities. Social Sciences and Arts, 7(1), 773-782.

Ellis, R. (2003). Task-Based Language Learning and Teaching. Oxford: Oxford University Press.

Griffith University. (2012). Research-Based Learning Strategies for successfully linking teaching and research. Retrieved from http://www.griffith.edu.au/gihe/pdf/gihe_tip sheet_web_rbl.pdf

Guilford, J. P. (1967). The Nature of Human Intelligence. McGraw-Hill, Book Company.

Hannongbua, S. (2016). Learning Management for Education 4.0 Learning Management for Education 4.0. Valaya Alongkorn Rajabhat University under the Royal Patronage of His Majesty the King.

Khamanee, T. (2005). Learning management by learners using research as part of learning process. Bangkok: Teachers Council of Thailand Ladprao Printing House.

Mangkhang, C. (2017). The Ideals of Social Studies for People Curriculum. Bangkok: Printing House of Chulalongkorn University.

Mangkhang, C., \& Kaewpanya, N. (2021). The Scenarios Perspective of Social Studies Pedagogy to Next Citizenshipin the 22nd Century. Turkish Online Journal of Qualitative Inquiry, 12(8), 5172-5180.

Mangkhang, C., Yimsawat, C., \& Kaewpanya, N. (2021). Creative learning innovation according to The King Bhumibol's Science through community economy for promoting green citizenship of secondary school students in upper northern special economic development zones, Thailand. Journal of Educational Innovation and Research, 5(2), 207-222.

Monthirat, K. (2016). Education Policy. Management and Leadership. Faculty of Education Chulalongkorn University.

Panich, W. (2012). Ways to create learning for students in the 21st century. Bangkok: Sodsri-Saritwong Foundation.

Phinlao, P. (2013). Proactive Learning of Social Studies Teachers in the Era of Thailand 4.0. Academic Journal of Education, 20(May-August 2013), 2365.

Sinlarat, P. (2016). The philosophy of creative education and productivity. Bangkok: Printing House of Chulalongkorn University.

. (2017). Education 4.0 is more than education. 4th printing. Bangkok: Printing House of Chulalongkorn University.

. (2017). Thai Education 4.0 Philosophy of Creative and Productive Education. 4th printing, Bangkok: Chulalongkorn University Printing House.

. (2017). How to think productively, teach and create. 2nd printing, Bangkok:Chulalongkorn University printing house.

. (2017). Creativity. How to teach and create. 2nd printing, Bangkok:Chulalongkorn University printing house.

Thiankasem, P., Ponthong, J., \& Yongsor, P. (2020). A Study of Creative Skills and Productivity for Students of Private Higher Education Institutions. Peace Studies Journal, 8(November-December 2020), 2302. 


\section{Copyrights}

Copyright for this article is retained by the author(s), with first publication rights granted to the journal.

This is an open-access article distributed under the terms and conditions of the Creative Commons Attribution license (http://creativecommons.org/licenses/by/4.0/). 